\title{
Orígenes del VIH/SIDA
}
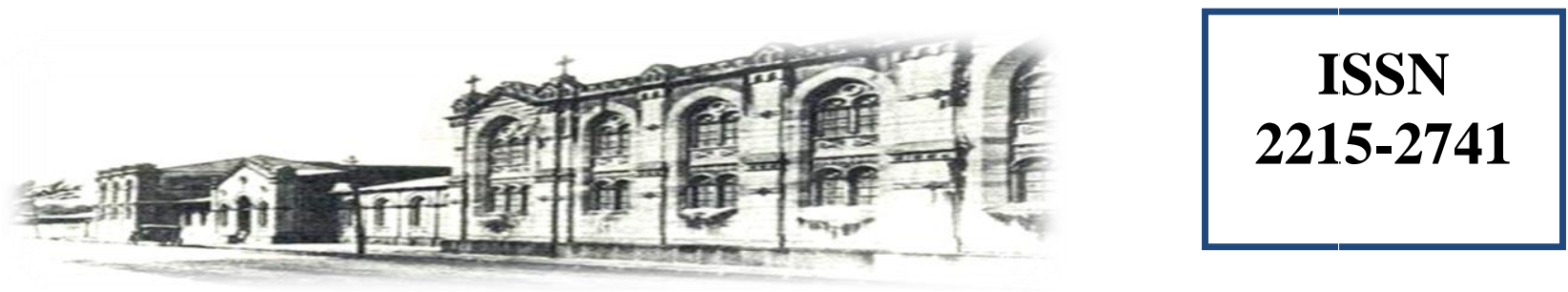

Hospital San Juan de Dios, San José, Costa Rica. Fundado en 1845

$\begin{array}{ll}\text { Recibido: } & 05 / 09 / 2016 \\ \text { Aceptado: } & 06 / 10 / 2016\end{array}$

Ricardo Boza Cordero ${ }^{1}$

${ }^{1}$ Médico Especialista en Infectología. Ex-Miembro Sección de Infectología - Hospital San Juan de Dios. Profesor Emérito de la Universidad de Costa Rica (pensionado). Correo electrónico: rbozac51@ gmail.com

\section{RESUMEN}

El síndrome de inmunodeficiencia adquirida (SIDA) es producido por dos lentivirus, los virus de la inmunodeficiencia humana (VIH) 1 y 2 . Los primeros pacientes fueron diagnosticados en Estados Unidos en 1981. El virus fue aislado e identificado en 1983, no obstante, sus orígenes no fueron dilucidados sino hasta tiempo después, el del VIH-2 a partir del virus de la inmunodeficiencia de simios (VIS) aislados de monos africanos principalmente Cercocebus spp y el VIH-1 de VIS aislados de chimpancés principalmente del género Pan troglodytes troglodytes. En este artículo se hace un análisis de los orígenes de estos virus así como de su posterior diseminación a África, América y el resto del mundo.

\begin{abstract}
Acquired immunodeficiency syndrome (AIDS) of humans is caused by two lentivirus, human immunodeficiency virus types 1 and 2(HIV 1 and 2). The firsts AIDS patients were diagnosed in USA in 1981 and the viruses were isolated and identified between 1983 and 1985, but its origins and evolution was elucited many years after. Both HIV are the result of multiple cross-species transmission of simian immunodeficiency viruses (SIV) naturally infecting African monkeys, HIV-2 from African monkeys Cercocebus spp and HIV-1 from chimpanzes Pan troglodytes troglodytes. Here we discuss the origins, early transmission, dissemination and establishment of the viruses in human populations in Africa, America and the rest of the world.
\end{abstract}




\section{INTRODUCCIÓN}

El SIDA (síndrome de inmunodeficiencia adquirida) es una de las enfermedades infecciosas más devastadoras en la historia de la humanidad. Aproximadamente 78 millones de personas han contraído la infección y han fallecido unas 35 millones de individuos por enfermedades asociadas al sida desde el inicio de la epidemia. ${ }^{1}$ Aun cuando el tratamiento antirretroviral ha disminuido la mortalidad por sida, el acceso a esta terapia no es universal, asimismo su curación y el desarrollo de una vacuna efectiva no son aún objetivos cercanos a mediano plazo.

En 1981 fueron diagnosticados en Estados Unidos los primeros pacientes con sida y en 1983 se identificó a un retrovirus de la familia de los lentivirus, el VIH o virus de la inmunodeficiencia humana VIH-1, como el causante de esta entidad clínica. En 1985 fue aislado un nuevo virus, el VIH-2, en pacientes con sida en África occidental. El objetivo de esta revisión es analizar los orígenes de estos retrovirus así como examinar las circunstancias que rodearon la aparición de esta enfermedad.

\section{HISTORIA}

Cuál era el ambiente médico científico alrededor de las enfermedades infecciosas que predominaba en los años 80 cuando se diagnosticaron los primeros pacientes con sida?

1. Durante la década de los años 70 se incrementó el interés sobre Pneumocystis carinii (actualmente P.jiroveci) para ese entonces considerado un parásito, ampliamente distribuido en la población sana, pero que producía infecciones principalmente pulmonares, severas, en personas inmunocomprometidas o con cáncer usualmente hematológico, con alta mortalidad. ${ }^{2}$

2. Desde finales de los años 60 y con mayor intensidad durante la década de los 80, las investigaciones sobre la red de regulación inmunológica y su relación con las enfermedades infecciosas, cobraron mucha relevancia, de tal forma que en 1972 GM Edelman y RR Porter recibieron el premio Nobel de Fisiología y Medicina por sus estudios sobre la estructura de los anticuerpos; B.
Benacerraf fue galardonado con ese premio en 1980 por sus aportes al conocimiento de los factores de las membranas celulares involucrados en el reconocimiento de antígenos (HLA, CMH o Complejos Mayores de Histocompatibilidad) y en 1984 fueron honrados con el premio Nobel en Fisiología y Medicina, JFK Kölner por el desarrollo teórico de los procesos involucrados en la respuesta inmunológica y NK Jerne y C Milstein por las investigaciones para el avance del conocimiento y la producción de los anticuerpos monoclonales.

Desde el punto de vista médico, estos adelantos en la inmunología se vieron plasmados en el desarrollo de nuevas técnicas para el diagnóstico y el tratamiento de las enfermedades infecciosas.

3. El desarrollo de la virología recibió un gran impulso a partir de los años 50 con la implementación de los cultivos de células en el laboratorio, lo que permitió el estudio de diversos virus patogénicos así como el desarrollo de las primeras vacunas contra enfermedades virales. JF Enders, FC Robbins y $\mathrm{TH}$ Weller recibieron el premio Nobel de Fisiología y Medicina en 1954 por sus trabajos en este campo.

El conocimiento de la epidemiología, la fisiopatología las manifestaciones clínicas y el diagnóstico de diversas virosis, entre ellas las producidas por los virus del grupo Herpes, se desarrollaron rápidamente en la segunda mitad del siglo XX. La mayoría de estos virus (CMV, Epstein Barr, virus Herpes 1-8) tienen la capacidad de interactuar con células del sistema inmunológico, induciendo alteraciones más o menos profundas en su funcionamiento, es decir, inmunosupresión.

4. En 1911, Peyton Rous, un joven médico que laboraba en el Instituto Rockefeller en New York, estudiando un tumor en pollos, fue capaz de reproducirlo en otros pollos mediante la inoculación de un filtrado del tumor original.

Descartó que se tratara de bacterias o parásitos y propuso como causa un "agente filtrable", al que luego se denominó Virus del Sarcoma de Rous(VSR); no obstante, su trabajo no tuvo mayores repercusiones, hasta que en los años 50 y 60, R Dulbecco, H Temin y D Baltimore trabajando con el VSR en la génesis de los tumores, lograron 
identificar una enzima de ese virus, la transcriptasa reversa, la cual era capaz de transformar el ARN viral en ADN y de esa forma integrarse en el ADN celular, es decir al genoma celular, lo que representó avances importantes en el conocimiento de la biología del cáncer.

Por esos trabajos, P Rous recibió el premio Nobel en Fisiología y Medicina en 1966 y R Dulbecco, H Temin y D Baltimore fueron acreedores a ese galardón en 1975 por sus aportes al conocimiento de los virus oncogénicos.

Así, el papel de los virus en la génesis de tumores fue un campo ampliamente desarrollado en los años 70 por sus repercusiones clínicas y terapéuticas.

En Estados Unidos, en el Instituto Nacional del Cáncer, se estableció un laboratorio dedicado al estudio de los retrovirus y virus relacionados a tumores( Laboratory of Tumor Cell Biology), liderado por muchos años por el Dr. Robert Gallo $\mathrm{y}$ visitado por gran cantidad de investigadores de todo el mundo, en donde se realizaron trabajos pioneros que aclararon el papel de algunos virus en la génesis de tumores y en otras patologías humanas, identificándose retrovirus como HTLVI y II, virus linfotróficos de células $\mathrm{T}$ humanas (VLTH) o anteriormente llamados virus asociados a leucemia de células T Humanas.

Estos virus tienen la capacidad de interactuar con las células $\mathrm{T}$ humanas induciendo un tipo de tumor y diversos grados de inmunosupresión al paciente.

Es en ese contexto que en 1981 el Dr. Michael Gottlieb de la UCLA (Universidad de California en Los Ángeles) así como el Dr. Alvin Friedman-Kien de New York publicaron en el boletín de los $\mathrm{CDC}^{3,4}$ a un grupo de hombres jóvenes, previamente sanos, homosexuales, varios con antecedentes de usar drogas endovenosas, con un extraño síndrome caracterizado por neumonía por P.carinii, candidiasis orofaríngea severa, sarcoma de Kaposi, un raro tumor presente en algunas poblaciones de la cuenca del Mediterráneo y algunas otras infecciones hasta entonces poco frecuentes.

En el número de N Engl J Med del 10 de diciembre de ese año, M Gottlieb y H Masur de New York ${ }^{5,6}$ publicaron los hallazgos de esta nueva entidad que denominaron separadamente "una nueva inmunodeficiencia adquirida o una manifestación inicial de una disfunción inmune celular" dados los hallazgos de las pruebas de función de la respuesta inmunológica en sus pacientes como eran linfopenia de células T, inversión en la relación de células $\mathrm{T}$ cooperadoras sobre células $\mathrm{T}$ supresoras, anergia cutánea a diversos antígenos, ausencia de una respuesta proliferativas de los linfocitos a diversos antígenos, concentraciones normales o altas de inmunoglobulinas y función normal de los neutrófilos y del complemento.

Posteriormente se demostró esta entidad clínica en diversas poblaciones y con el desarrollo de la prueba serológica ELISA en 1985, se puso de manifiesto que era una pandemia.

En 1982 se le denominó SIDA o Síndrome de Inmunodeficiencia Adquirida; sin embargo su etiología no se aclaró hasta 1983 cuando un grupo de científicos franceses liderados por Françoise Barré-Sinoussi y Luc Montagnier del Instituto Pasteur de París lograron aislar e identificar un retrovirus en un hombre homosexual con linfadenopatía crónica, al que denominaron LAV o virus asociado a la linfadenopatía ${ }^{7}$, un nuevo retrovirus, pero a diferencia del grupo de Robert Gallo, quienes también aislaron de pacientes con este síndrome un virus, no lo consideraron perteneciente a los $\mathrm{VLTH}^{8}$.

Una gran discusión se planteó sobre quiénes habían sido los primeros en identificar este agente y se concluyó que el virus estudiado por el grupo de Gallo et al era el mismo que el aislado en Francia, habiendo este contaminado los cultivos celulares en Estados Unidos como parte del trasiego de muestras; de tal forma que no era un VLTH sino un nuevo retrovirus como habían planteado los investigadores franceses desde un inicio y que a partir de 1984 se denominó VIH o virus de la inmunodeficiencia humana.

En 2008 les fue concedido el premio Nobel en Fisiología y Medicina a F Barré-Sinoussi y L Montagnier por ese descubrimiento.

\section{ORÍGENES DEL VIH/SIDA}

La pregunta ahora es ¿cuál es el origen de este nuevo retrovirus? Debemos recordar que han sido identificados otros retrovirus y lentivirus en humanos, así como en diversas especies de animales $^{9}$ (Fig 1). 
Muchas teorías conspirativas fueron publicadas inmediatamente después del aislamiento y la identificación del VIH, las que no entraremos a discutir por carecer de bases científicas. Como todo en la ciencia, existen siempre antecedentes sobre investigaciones que llevaron al aislamiento, identificación y origen del VIH.

Como decíamos anteriormente, desde los trabajos de P.Rous, hubo mucho interés en la relación entre virus y cáncer. En 1973 fue publicado un trabajo sobre la transmisión horizontal entre felinos del virus de la leucemia felina, un retrovirus ${ }^{10}$.

Este virus se creía hasta entonces que solo se transmitía de forma vertical de madre a hijos. Además, no solo producía cáncer en felinos, sino una inmunosupresión severa que los llevaba a la muerte. En este trabajo quedaron bien establecidos ambos conceptos sobre este virus, es decir, su transmisión horizontal (por medio de heridas entre felinos) y la aparición de la inmunodeficiencia ya comentada.

En los años 70 se fue perdiendo el interés sobre el tema de la relación cáncer-virus y este trabajo no tuvo mucho impacto en la comunidad científica ya que se llegó a considerar a los retrovirus como meras curiosidades biológicas.

Aun cuando muy importantes en la comprensión de la oncogénesis, todas esas investigaciones tuvieron pocas repercusiones en la medicina clínica; aún más, los dos VLTH estudiados solo fueron asociados a una rara forma de leucemia-linfoma de células $\mathrm{T}$, a una mielopatía denominada paraparesis espástica tropical y otras pocas entidades infrecuentes en la práctica clínica ${ }^{11}$.

La aparición de los primeros casos de sida a principios de los años 80 no solo llamó la atención de los médicos tratantes de esos pacientes.

El Dr. Donald Francis, había realizado sus estudios de postgrado sobre el virus de la leucemia/inmunodeficiencia de felinos en la Universidad de Harvard con el Dr. Myron Essex, experto en esta patología, coautor del trabajo anteriormente citado de 1973 sobre este virus.

El Dr. Francis había laborado para los CDC en el análisis de la hepatitis B en la comunidad de hombres homosexuales y había sido trasladado para cooperar en el estudio de esta nueva epidemia.
Desde un principio, uniendo sus conocimientos en estas patologías, pensó en la posibilidad de un retrovirus como agente etiológico del sida, el cual se transmitía como la hepatitis $\mathrm{B}$, por sangre y sus derivados y por relaciones sexuales y así se lo manifestó al Dr. Essex.

No obstante, su trabajo era sobre aspectos epidemiológicos del sida ${ }^{12}$ y al final se involucró en las luchas sociales de la comunidad gay, abandonando los estudios sobre la etiología de esta nueva epidemia. Su participación en los primeros años de esta dolencia quedó plasmado en la galardonada película "And the Band Played On" de 1993.

En 1983, una estudiante de postgrado, Patricia Kanki, mientras realizaba sus estudios en el Centro de Investigación de Primates en Boston, empezó a observar la muerte de varios macacos procedentes de Asia debido a una rara enfermedad, la cual les producía una profunda inmunosupresión con conteos bajos de linfocitos T CD4+ y se asociaba diarrea y otras enfermedades oportunistas.

El Dr. Essex fue informado de estos hallazgos y con las técnicas usuales para el estudio de estos virus, identificaron un nuevo retrovirus en la sangre de esos monos, el cual no producía enfermedad en monos africanos.

En ese mismo orden, lograron identificar anticuerpos contra el virus recién aislado en monos africanos cautivos, pero ese virus reaccionaba muy débilmente contra anticuerpos del VIH, es decir, era un retrovirus nuevo aislado de monos asiáticos, se encontraba en monos africanos sin producirles enfermedad pero era diferente al VIH. Se le denominó entonces virus de la inmunodeficiencia de simios o VIS ${ }^{13}$.

En 1985, Montagnier et $\mathrm{al}^{14}$ aislaron e identificaron un nuevo retrovirus de dos paciente con sida, procedentes de Guinea Bissau y las Islas de Cabo Verde, diferente al VIH, al cual denominaron VIH-2. Este virus era similar al que habían estudiado P.Kanki y M Essex en sus monos en Massachusetts ${ }^{14}$.

Hasta el momento el VIS solo había sido identificado en monos en cautiverio por lo que varios grupos de científicos se trasladaron a África 
occidental, con el fin de investigar la presencia del VIS en animales salvajes.

El grupo de investigadores liderado por P Kanki y $M$ Essex encontraron que tanto en monos en cautiverio como salvajes de un tipo denominado monos verdes, procedentes de África occidental, mostraban seropositividad para el VIS entre 30$70 \%$ de los individuos, sin mostrar enfermedad alguna. De igual forma, en trabajadoras del sexo senegalesas, lograron identificar un virus diferente al VIH inicial pero similar al VIH aislado por Montagnier et al de los pacientes de Guinea Bissau y Cabo Verde ${ }^{14}$.

De esta forma habían sido descubierto dos tipos de $\mathrm{VIH}$, uno poco frecuente, claramente originario de África occidental asociado al VIS de los monos verdes y otro, el más frecuente, causante de la pandemia que asolaba al mundo, cuyo origen se desconocía hasta el momento. Al primero se le denominó VIH-2 y al otro VIH-1.

En 1987 fue secuenciado el genoma del VIH-2 ${ }^{15}$. El genoma del VIH-1 ya había sido analizado desde $1985^{16}$.

El término "mono verde" según los primatólogos, es muy confuso y ambiguo, no permite un estudio adecuado porque en diferentes lugares de África, diferentes géneros reciben ese nombre. En sentido estricto, estos pertenecerían al género Chlorocebus ${ }^{17}$.

Sin embargo otro mono africano es más importante en esta historia. En 1979, en un centro para primates en Louisiana, Estados Unidos, monos denominados "tiznados" (sooty mangabey en inglés, Cercocebus atys) estaban siendo estudiados por presentar lesiones similares a la enfermedad de Hansen.

Como se sabe, esta enfermedad es exclusiva de los seres humanos y difícil de transmitir a otros animales excepto al armadillo (Dasypus spp). Para mayor análisis, fueron trasladados a otro centro de primates, donde entraron en contacto con monos provenientes de Asia. Varios de estos animales recibieron inyecciones de las lesiones de los monos africanos, desarrollando rápidamente úlceras extensas en la piel, pero inesperadamente comenzaron a fallecer por diarrea, pérdida de peso y diversas enfermedades infecciosas.
A los cuidadores les llamó la atención esta situación y lo relacionaron con el sida en humanos, que para esa época (1983) estaba en boga en los Estados Unidos. De estos monos se logró aislar VIS ${ }^{17,18}$.

De esta manera, se trasladaron a África Occidental varios grupos de científicos y aislaron de Cercocebus spp gran cantidad de VIS que a partir de entonces se denominaron VIS $\mathrm{V}_{\mathrm{smm}}$ (de sooty mangabey monkey). Los procedentes de monos asiáticos, fueron denominados VIS $_{\text {mac }}$ (de macacos

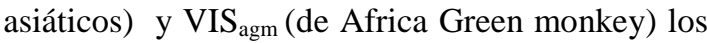
encontrados en los monos verdes ${ }^{13}$.

Quedó establecido que el VIH-2 es una zoonosis, originario del VIS, frecuente en monos de África occidental. Además de esta diferencia en su origen, el VIH-2 diverge del VH-1 en más de 50\% de su genoma, no tiene gene $v p u$, en su lugar posee el gene $v p x$. Los anticuerpos contra VIH-2 no reaccionan contra proteínas del envoltorio del VIH1 y viceversa, por eso deben realizarse detecciones serológicas por separado de ambos virus. Además el VIH-2 es menos patogénico que el VIH- ${ }^{19}$.

El mono tiznado se encuentra en África Occidental fundamentalmente, desde Gabón hasta Ghana, en zonas selváticas, pero también en plantaciones de palma y arroz. Vive en árboles pero es muy frecuente encontrarlos en el suelo, buscando semillas, frutos y raíces.

Son pequeños, fácilmente son cazados por los humanos para alimentarse y en ocasiones son utilizados como mascotas ${ }^{17}$ (Fig 2).

En esos países es frecuente encontrarlos en mercados, en carnicerías, vendiéndose como alimento. De tal forma, han vivido en estrecha relación con el ser humano (Fig 3).

Y ¿qué sucedió con el origen del VIH-1? Con lo expuesto anteriormente quedaba claro el origen del VIH-2, pero no del VIH-1.

A finales de los años 80, solo había sido posible aislar unos pocos VIS de algunos chimpancés en cautiverio, que por su comportamiento serológico se consideraban más cercanos al VIH-1 que al VIH-2.

Se realizaron estudios de genética molecular a estos pocos aislamientos (cuatro cepas hasta 1998 de VIS $_{\text {cpz }}$ o virus de inmunodeficiencia de simios de chimpancés) donde se demostraba la cercanía al 
VIH-1, sin embargo, en chimpancés salvajes había sido muy difícil identificarlos. Esto provocó desinterés en la comunidad científica internacional sobre los estudios para determinar el origen del VIH-1. Además, la falta de interés de las autoridades de ONUSIDA para realizar este tipo de investigaciones, alegando que había en ese momento otro tipo de prioridades en cuanto al $\mathrm{VIH} /$ sida, dio como resultado que fuese hasta inicios del siglo XXI que se reiniciaron estos análisis $^{18}$.

Con la secuenciación del virus en 1985, se notó una gran diversidad en los aislamientos en seres humanos, lo cual se explicaría por la alta tasa de replicación viral, aproximadamente $10 \mathrm{mil}$ millones de copias por día y la gran cantidad de errores que se producen en la actividad de la transcriptasa reversa ${ }^{19}$.

Cuando se comparan diversas cepas de VIH, la semejanza entre secuencias de nucleótidos en sus genomas se llama homología y la "no-similitud" se denomina divergencia. Si $90 \%$ de la secuencia de nucleótidos entre dos aislamientos es la misma, entonces poseen $90 \%$ de homología o $10 \%$ de divergencia. Por ejemplo VIH-1 tiene 50\% de divergencia con el VIH-2, por lo que son dos especies diferentes. Si hay divergencia entre 10$20 \%$ entre las cepas, se clasifican en grupos diferentes.

De esta forma, VIH-1 se divide en cuatro grupos: M (main o principal), responsable por el $99 \%$ de los casos de la actual pandemia; O (outlier o "atípico"); $\mathrm{N}$ (ni M ni O) y P (solo encontrado en África) ${ }^{19}$.

El grupo $M$ se divide en nueve subtipos a saber: A B C D F G J H K. Además las reinfecciones con subtipos son frecuentes, lo que lleva a la aparición de cepas recombinantes, de las que se han identificado 48 hasta el momento. Se nombran por los subtipos recombinados, por ejemplo CRF02_AG, están involucrados los subtipos A y G (Fig 4).

Se ha establecido relación entre algunos subtipos y mortalidad, por ejemplo el D evoluciona más rápidamente. De la misma forma, en Latinoamérica, Norteamérica y Europa entre 80-95\% de los aislamientos pertenecen al subtipo $\mathrm{B}$, introducido principalmente por relaciones homosexuales entre hombres; en Europa del Este y en Asia, el subtipo A es el predominante, ya que el mecanismo principal de diseminación fue por el compartir agujas más que sexual.

La prevalencia de estos grupos y subtipos ha servido también para estudiar la evolución de la epidemia, entre más diversidad de subtipos, más antigua la introducción de los virus. Por ejemplo, en países de África central como República Democrática del Congo, Camerún, y Gabón, es donde se encuentra la mayor diversidad de grupos, subtipos y recombinantes, lo que hace pensar que en esa región se originó la pandemia ${ }^{18}$ (Fig 5).

\section{¿Cuál es el papel que han jugado los chimpancés en esta epidemia?}

Los chimpancés son los primates más cercanos al ser humano; comparten entre $98-99 \%$ de su genoma con el nuestro; se considera que provenimos de un mismo ancestro del cual nos separamos hace unos 4 millones de años.

Son los animales no humanos más inteligentes, poseen su propias personalidades, la mayoría son muy sociables, viven en grupos o manadas, en la selva, en árboles pero también son terrestres, caminan en cuatro patas, pero en ocasiones lo hacen erguidos, son omnívoros, inclusive comen algunos animales pequeños y monos, son malos nadadores. Aún hoy en día y a pesar de la prohibición para ser cazados, son utilizados como alimento y para ser vendidos ${ }^{18}$.

Se clasifican en dos grandes géneros: Pan troglodytes y Pan paniscus o bonobos. Recientemente Pan troglodytes se ha clasificado en cuatro subespecies a saber, Pan troglodytes verus, Pan troglodytes ellioti, Pan troglodytes schweinfurtii y Pan troglodytes troglodytes, que tienen gran importancia en la epidemiolgía del $\mathrm{VIS}_{\mathrm{cpz}}$ y por lo tanto en la aparición del VIH-1.

Por ser malos nadadores, estas especies están ubicadas geográficamente, sirviendo los grandes ríos como fronteras naturales. $P$ t. troglodytes vive al sur del río Sangha, al sureste de Camerún y en algunas otras regiones del África central ${ }^{18}$ (Fig 2 y 6).

Como decíamos anteriormente, en 1999 se tenían únicamente cuatro cepas aisladas de VIS $_{\mathrm{cpz}}$ con las que fue posible realizar estudios filogenéticos denominados "relojes marcadores genéticos" y determinar que el VIH-1 se originó de VIS $_{\mathrm{cpz}}$ de 
Pan troglodytes troglodytes. El reto era que los aislamientos eran de chimpancés en cautiverio.

Utilizando sustancias inhibidoras de proteasas, enzimas frecuentes en las heces y que destruyen a los virus, se lograron identificar en heces de Pan troglodytes troglodytes salvajes en diversas regiones del África central, cepas de VIS cpz similares a las anteriores y cercanas a los grupos $\mathrm{M}$ y $\mathrm{N}$ del VIH-1; de las otras subespecies de chimpancés fueron aislados pocos virus pero filogenéticamente lejanos al VIH-1 ${ }^{20}$.

Con estos estudios especiales en cepas de VIS, así como de VIH aisladas de enfermos en África y de dos cepas humanas recuperadas en antiguos laboratorios de Kinshasa, República Democrática del Congo, en 1959 y 1960, las más antiguas que se tengan conocimiento, se demostró el origen del VIH-1, grupo M así como la zona geográfica de procedencia.

Nuevamente utilizando análisis evolutivo genético de las cepas de VIH-1, se logró determinar que posteriormente al salto interespecies del SIV de chimpancés al ser humano ocurrido aproximadamente entre 1910-1920 en la esquina sureste de Camerún a orillas del río Sangha, por medio de una ruta fluvial, fue transportado por un individuo infectado a la capital del antiguo Congo belga, Leopoldville (actuales República Democrática del Congo y Kinshasa respectivamente) y de aquí la posterior diseminación se llevó a cabo entre 1920 y 1960 hacia el sur hacia Katanga, Likasi y Lubumbashi, ciudades importantes en esas épocas por la explotación de diamantes, caucho y marfil por parte de colonizadores europeos ${ }^{21}$ (Fig 6).

Asimismo la ruta hacia el mar, Brazzaville y Pointe-Noire, este último puerto importante de la República del Congo sobre el Atlántico y punto de salida de todas estas mercancías hacia Europa, fue posteriormente seguida durante los años 19301960. Después de 1960 se extendió hacia el norte, hasta la ciudad de Kisangani. Estas rutas eran transitadas por pobladores locales por ferrys, barcos y por ferrocarriles ${ }^{20}$.

¿De dónde adquirieron el VIS los chimpancés? Nuevamente, por estudios filogenéticos de biología molecular, se ha postulado que otros monos africanos como los de los géneros Cercocebus y Chlorocebus infectaron con VIS a los chimpancés.
Igualmente se ha observado sida en algunos chimpancés, contrario a lo que se creía anteriormente, que el VIS era no patogénico para esta especie de primates. Esto demuestra que el sida es anterior al $\mathrm{VIH}^{20-22}$.

Varias son las diferencias importantes entre VIH y VIS desde el punto de vista de sus genomas; la infección con VIS de los primeros seres humanos creó una presión selectiva sobre este virus con el fin de superar los mecanismos de defensa del hospedero, del ser humano, lo que dio origen al $\mathrm{VIH}^{21}$.

De forma muy resumida, VIH del grupo M poseen un gene, $v p u$ que codifica proteínas con función anti-CD4+ y con actividad "antitetherina". Esta proteína, tiene acción antiviral contra el VIH y contra VIS, al formar ataduras o anclajes con el virus, impidiendo su liberación. No obstante en VIS esta actividad "antitetherina" es codificada por el gene nef diferente al ser humano ${ }^{20-22}$. La evolución de las proteínas producidas por estos genes podría explicar la patogenicidad de VIS en monos y en chimpancés y del VIH en el ser humano ${ }^{20-22}$.

Diversos autores han planteado varias hipótesis que explicarían la diseminación extensa del VIH/sida a partir de la década de los $60^{17,18}$.

En los años 50 y 60 se dio un gran proceso de urbanización, de migración de zonas rurales a centros de población como Kinshasa, con aumento de la prostitución; además se realizaron en África grandes campañas para el control de enfermedades tropicales como la malaria, la lepra, la tuberculosis, la enfermedad del sueño o tripanosomiasis africana que causaba alta morbi-mortalidad en diversas regiones.

Para esto se utilizaban medicamentos inyectables, pero las condiciones sanitarias no eran las mejores, por lo que la posibilidad de la transmisión parenteral del VIH así como de otras enfermedades era muy alta.

Por otro lado, las guerras internas de liberación de la colonización europea desde los años 50 en muchas regiones de África central y occidental, produjeron un gran caos socio-económico, con grandes migraciones de poblaciones, hambrunas y múltiples enfermedades. 
Con respecto a la extensión fuera de África, se ha propuesto, basados en datos seroepidemiológicos y periodísticos, que en los años 60 y 70 fueron contratados profesionales haitianos(por su cercanía racial y lingüística) por el gobierno de Zaire, antiguo Congo Belga, para tratar de remediar la falta de trabajadores especializados que produjo las guerras de independencia.

A finales de los años $60 \mathrm{y}$ principios de los años 70, la mayoría de ellos retornaron a Haití, algunos probablemente infectados con VIH. Por otro lado, en ese país, eran frecuentes los centros oficiales y clandestinos de donadores de sangre, no todos de donadores voluntarios, para ser vendida al exterior, principalmente hacia Estados Unidos y Europa. En esos años, no se realizaban de rutina tamizajes para enfermedades infecciosas en la sangre donada. De igual manera en los años 70 aumentaron las excursiones de hombres y en menor medida de mujeres de Europa y los Estados Unidos a Haití con fines de turismo sexual.

De tal forma, algunos haitianos infectados con VIH probablemente contaminaron la sangre y productos derivados de ella que se exportaba así como a homosexuales hombres turistas los cuales volvieron a sus países y diseminaron el virus. Se estima, según estudios filogenéticos, que el VIH fue introducido en Haití cerca del año 1966, antes que en Estados Unidos.

Estudios serológicos han demostrado que en 1979, $33 \%$ de los adictos a drogas endovenosas en New York estaban infectados con VIH.

En 1969 ocurrieron disturbios en un bar gay y de lesbianas en New York, Stonewall, debido a la persecución policial a esta comunidad, que desde los años 50 venía siendo acosada en diferentes ciudades del país. Esto provocó una migración de estos grupos a ciudades como San Francisco y Los Ángeles, con mayor libertad y tolerancia. En 1978, $6 \%$ de los hombres gay en San Francisco eran VIH+.

La libertad sexual, sin el uso de medidas de protección adecuadas en esos grupos así como la donación pagada e indiscriminada de sangre, sirvió como amplificación de la expansión del VIH en esas y otras comunidades.Es en este ambiente que el Dr. Michael Gottlieb diagnosticó los primeros pacientes con sida en Los Ángeles.

\section{CONCLUSIONES}

El Síndrome de Inmunodeficiencia Adquirida (SIDA) fue reconocido como una nueva entidad clínica en 1981 en Estados Unidos, cuando un número creciente de hombres jóvenes con antecedente de relaciones homosexuales y de uso de drogas recreativas endovenosas, fallecían de infecciones oportunistas y de cánceres poco usuales. Poco tiempo después fue identificado un nuevo retrovirus (virus de la inmunodeficiencia humana o VIH) como el agente causante, origen de una de las enfermedades infecciosas con mayor mortalidad en la historia de la humanidad.

Desde el descubrimiento del VIH se realizaron intensos estudios por esclarecer su súbita aparición, la diseminación pandémica y su patogénesis.

En los años 80 se avanzó en el esclarecimiento de su origen, al aislar un retrovirus denominado virus de la inmunodeficiencia de simios o VIS, de monos cautivos y luego de monos en su hábitat natural en África occidental, los denominados monos verdes (Chlorocebus spp ) pero principalmente de los monos tiznados (Cercocebus atys).

Asimismo a mediados de los años 80 se logró identificar en un paciente con SIDA proveniente de África occidental, un virus diferente al de los pacientes hasta ahora estudiados, el que se denominó VIH-2, similar al VIS. Así el VIH-2 se originó de VIS aislado de monos africanos tiznados por lo que se denominó VIS $_{\text {smm }}$ o VIH de sooty mangabey monkey (en lengua inglesa).

Desde finales de los años 80 se inició la búsqueda del origen animal del VIH-1, pero no es sino hasta finales de los años 90, en que investigadores que se trasladaron a África occidental y central, lograron aislar e identificar un virus de chimpancés al que se denominó VIS $\mathrm{Cpz}_{\mathrm{cz}}$ como el ancestro más cercano del VIH-1.

Así por medio de estudios filogenéticos de las cepas aisladas lograron ubicar cuándo y dónde aproximadamente ocurrió el salto interespecie de este virus. Es posible que cazadores de chimpancés en esa zona se contaminasen del VIS $\mathrm{Cpz}_{\mathrm{c} z}$ al cazar y destazar monos para consumo humano.

Se logró situar este acontecimiento entre 19101920 en el sureste de Camerún, a orillas del río 
Sangha, de donde se distribuyó a la capital del antiguo Congo Belga, Leopoldville y de ahí al resto del ciudades de África Central.

Esta diseminación fue favorecida por los cambios sociopolíticos y económicos, la urbanización, el incremento de la prostitución, así como al caos social asociado a las guerras de liberación que acaecieron en las décadas de los 50 y 60 en las antiguas colonias europeas del centro y oeste de África, así como por la transmisión parenteral derivada de las campañas para tratar diversas enfermedades tropicales con medicamentos inyectables sin mayores cuidados sanitarios en el uso de jeringas.

El paso del VIH-1 a América se ha relacionado con la migración de trabajadores haitianos reclutados principalmente en Zaire para paliar la falta de profesionales que se dio posterior a la guerra de liberación en ese país y su ulterior retorno a Haití a finales de los años 60.

Estudios serológicos y filogenéticos así como periodísticos indican que en ese país, en esa época, se establecieron centros de donación de sangre con pocos controles sanitarios, para ser exportada a Estados Unidos y a Europa. Asimismo, el turismo sexual se incrementó; ambos factores permitieron el paso del VIH-1 a los Estados Unidos. Se estima que el VIH-1 ingresó a Haití cerca de 1966.

La represión policial hacia los grupos gay, una de las colectividades más afectadas por esta epidemia, hizo que buscaran nuevos sitios donde vivir con mayor libertad, trasladándose a diversas ciudades de California. Con esto se cierra el círculo del origen y posterior diseminación de la epidemia del VIH-1 en occidente.

\section{BIBLIOGRAFÍA}

1. ONUSIDA Reporte Global El Sida en cifras 2016 Ginebra Suiza

2. Hughes WT Pneumocystis carinii pneumonia N Engl J Med 1977;297:1381-1383

3. Gottlieb MS Schanker HM Fan PT et al Pneumocystis pneumonia. Los Ángeles MMWR 1981;30:250-252
4. Friedman-Kien A Laubenstein L Marmor M et al Kaposi's sarcoma and Pneumocystis pneumonia among homosexual men. New York and California MMWR 1981;30:305308

5. Gottlieb MS Schroff R Schanker HM et al Pneumocystis carinii pneumonia and mucosal candidiasis in previously healthy homosexual men. Evidence of a new acquired cellular immunodeficiency $\mathrm{N}$ Engl J Med 1981;305:1425-1431

6. Masur H Michelle MA Greene JB et al An outbreak of community-acquired Pneumocystis carinii pneumonia. Initial manifestation of cellular immune dysfunction N Engl J Med 1981;305:1431-1438

7. Barre-Sinoussi F Chermann JC Rey F et al Isolation of a T-lymphotropic retrovirus from a patient at risk for acquired immune deficiency syndrome (AIDS) Science 1983;220:868-871

8. Gallo RC Sarin PS Gelmann EP et al Isolation of human T-cell leukemia virus in acquired immune deficiency syndrome(AIDS) Science 1983;220:865-867

9. Goff SP Retroviridae: The Retrovirus and Their Replication Fields Virology Fifth edition Lippincott Williams \& Wilkins 2007;20002069

10. Hardy W Old LJ Hess PH et al Horizontal Transmission of Feline Leukemia Virus Nature 1973;244:266-268

11. Murphy EL Biswas HH Human T-Cell Lymphotropic Virus Types I and II in Mandell, Douglas and Bennett's Principles and Practice of Infectious Diseases Seventh Edition Churchill Livigstone 2010;2303-2322

12. Francis DP Curran JW Essex M Epidemic Acquired Immunodeficiency Syndrome. Epidemiological Evidence for a Transmissible Agent J Natl Cancer Inst 1983;71:5-9 
13. Kanki P Essex M Virology in Mayer K Pizer $\mathrm{HF}$ ed. The AIDS Pandemic Impact on Science and Society Elsevier 2005

14. Clavel F Guetard D Brun-Vezinet F et al Isolation of a new human retrovirus from West African patients with AIDS Science 1986;233:343-346

15. Guyader M Emerman M Somgo $\mathrm{P}$ et al Genome organization and transactivation of HIV type 2 Nature 1987;326:662-669

16. Ratner L Haseltine W Patanca $\mathrm{R}$ et al Complete nucleotide sequence of the AIDS virus HTLV III Nature 1985;313:277-284

17. Quammen D The Chimp and The River. How Aids Emerged from an African Forest WW Norton\& Co. 2015

18. Pepin J The Origins of AIDS Cambridge University Press 2011

19. Levy JA HIV and the Pathogenesis of AIDS ASM Press 2007

20. Sharp PM Hahn B The evolution of HIV and the origin of AIDS Phil Trans $\mathrm{R}$ Soc $\mathrm{B}$ 2010;365:2487-2494

21. Sharp PM Hanh BH Origins of HIV and the AIDS Pandemic Cold Spring Harb Perspect Med 2011;1:a006841

22. Faria NR Rambaut A Suchard MA et al The early spread and epidemic ignition of HIV-1 in human populations Science 2014;346:56-61

\section{ANEXOS}

\section{CONFLICTO DE INTERÉS Y/O AGRADECIMIENTOS}

Los autores declaran que no existió ningún conflicto de interés en el presente reporte. 


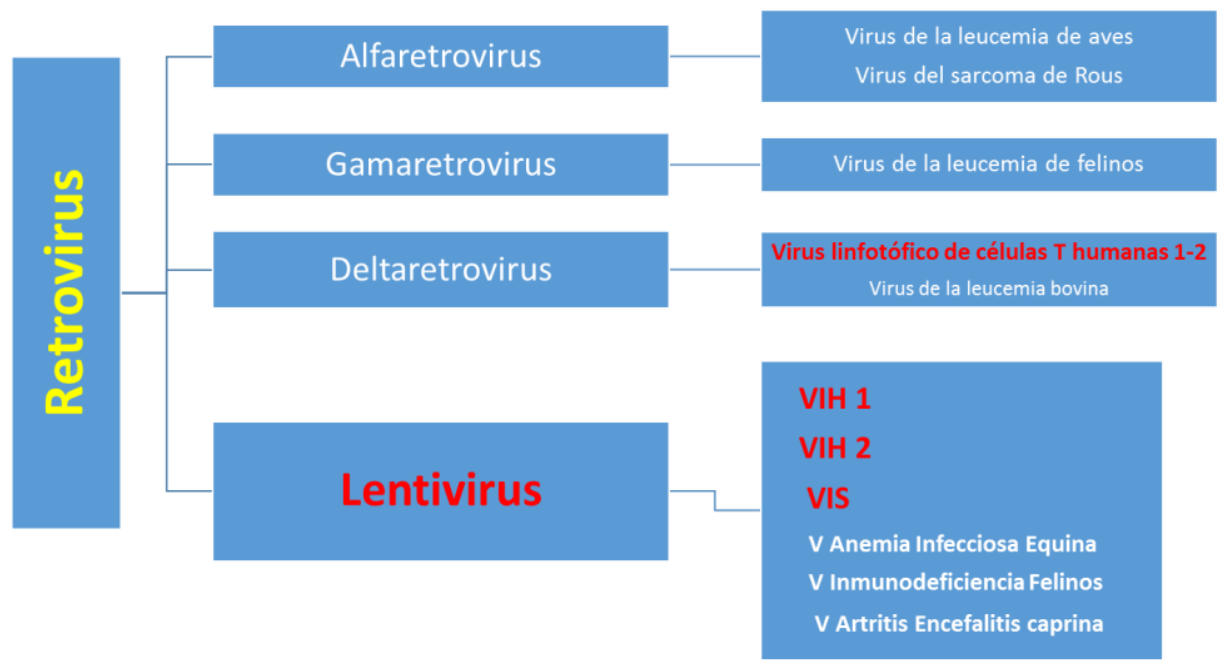

Figura 1. Orígenes del VIH/sida Taxonomía de algunos Retrovirus

Fuente: Adaptado de Fields Virology 2010

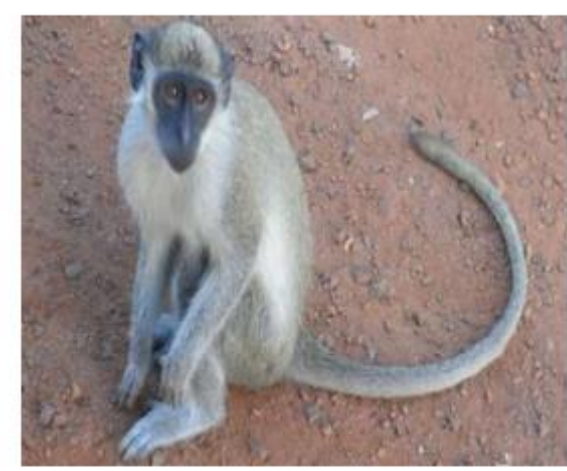

Chlorocebus spp

Mono verde

Portador de VIS $\mathrm{Vam}_{\mathrm{n}}$

Virus de la inmunodeficiencia de simios (affica green monker)

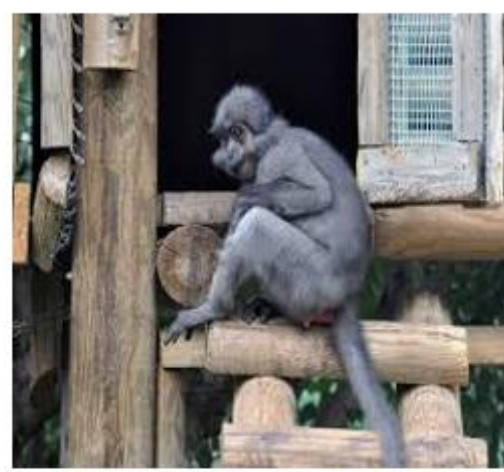

Cercocebus spp

Mono tiznado

Sooty mangabey

Pricipal portador de VIS smm $_{\text {sm }}$

Virus de la inmudoficiencia de simios

(sooty mangabey monkey)

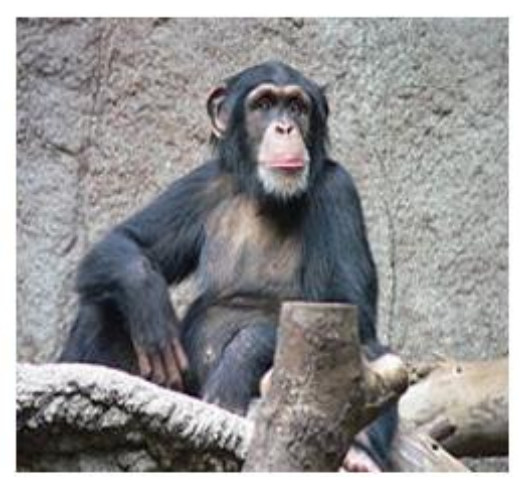

Pan troglodvtes

Chimpancé. Es un primate Principal portador de VIS $\mathrm{V}_{c z}$ Virus de la inmunofeficiencia de simios (chingunze)

Algunos presentan sida

Figura 2. Monos africanos asociados al VIH/SIDA

Fuente: Adaptado de Fields Virology 2010 

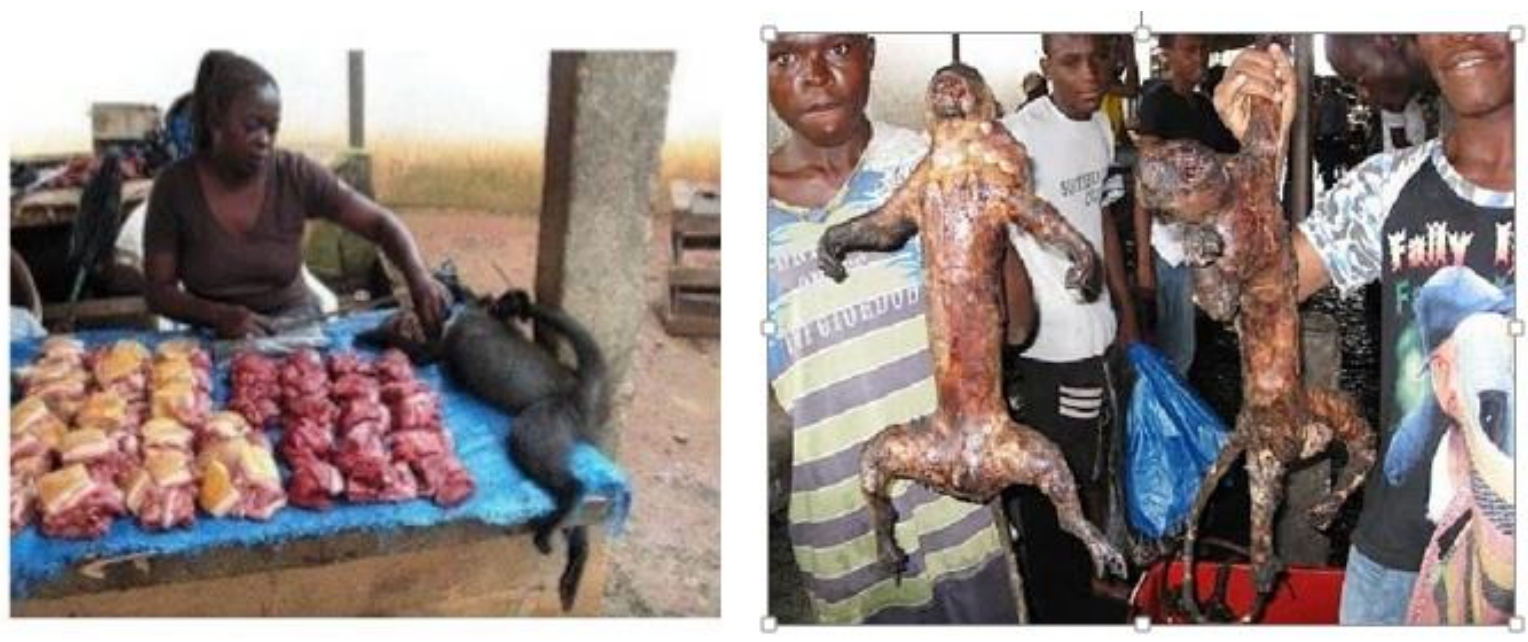

Figura 3. Comercio con monos en un mercado de África Occidental

Fuente: Adaptado de Fields Virology 2010
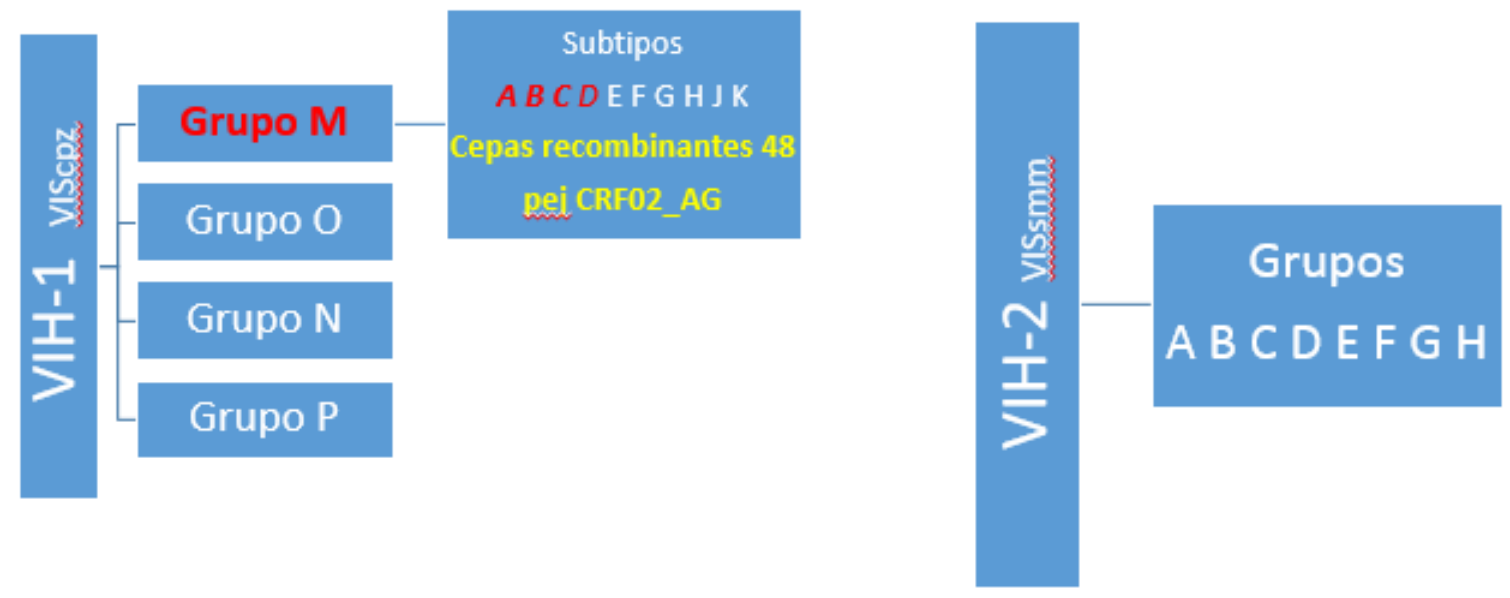

Figura 4. Clasificación del VI1 y VIH2

Fuente: Adaptado de Fields Virology 2010 


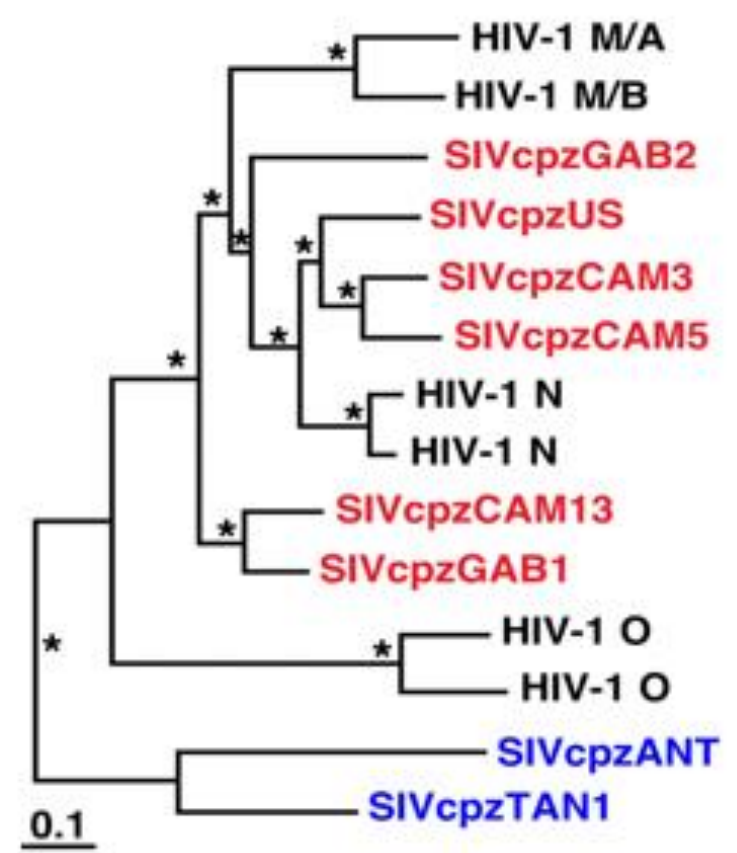

Figura 5. Orígenes del VIH/sida. Mapa filogenético de VIH/VIS utilizando técnicas de biología molecular, se logró establecer un reloj filogenético para determinar el origen de $\mathrm{VIH}$ a partir de VIS según la homología de los diversos genomas. A la izquierda el ancestro que dio origen a ambos virus (19-21)

Fuente: Adaptado de Fields Virology 2010 